\title{
Формирование и свойства захороненного изолирующего слоя двуокиси кремния в двухслойных структурах „пористый кремний-на-изоляторе“
}

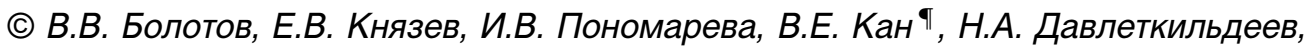 \\ К.Е. Ивлев, В.Е. Росликов
}

Омский научный центр Сибирского отделения Российской академии наук, 644024 Омск, Россия

ฯ E-mail: kan@obisp.oscsbras.ru

(Получена 24 марта 2016 г. Принята к печати 4 апреля 2016 г.)

Изучен процесс окисления мезопористого кремния в двухслойной структуре „макропористый кремний-мезопористый кремний“. Методами электронной микроскопии, эллипсометрии, электрофизическими измерениями исследована морфология и диэлектрические свойства получаемого слоя захороненного диэлектрика. Определено наличие специфического вида дефектов „шипов“, возникающих при окислении стенок макропор в макропористом кремнии, границ пересечения фронтов окисления мезопористого кремния. Установлено, что при исходной пористости мезопористого кремния $60 \%$ и трехстадийном термическом окислении формируются захороненные слои двуокиси кремния с напряженностью электрического поля пробоя $E_{\mathrm{br}} \sim 10^{4}-10^{5} \mathrm{~B} / \mathrm{cm}$. Показана перспективность применения многослойных структур „пористый кремний-на-изоляторе“ в интегрированных химических микро- и наносенсорах.

DOI: 10.21883/FTP.2017.01.43995.8246

\section{1. Введение}

Структуры на основе пористого кремния легко интегрируются с электронным обрамлением в кремниевом технологическом цикле и благодаря развитой поверхности могут служить основой для создания композитных структур для химических микро- и наносенсоров [1-7]. Для использования преимуществ развитой поверхности макропористого слоя в композитных структурах необходима электрическая изоляция этого слоя от проводящей подложки. В этом случае при нанесении чувствительной среды на развитую поверхность макропористого кремния можно получить многослойную интегрированную сенсорную структуру с большой эффективной площадью и, как следствие, с высокой чувствительностью.

В работах $[8,9]$ показана возможность изоляции слоя макропористогого кремния путем создания двухслойной структуры с захороненным слоем изолятора.

Цель настоящей работы заключалась в исследовании процесса формирования и свойств захороненного изолирующего слоя двуокиси кремния, а также определении режимов получения для достижения оптимальной структуры и диэлектрических параметров изолирующего слоя в многослойных сенсорных структурах на основе окисленного пористого кремния.

\section{2. Методика эксперимента}

Двухслойные структуры, состоящие из внешнего слоя макропористого кремния и захороненного слоя мезопористого кремния, были получены на полированных пластинах монокристаллического кремния $p$-типа марки КДБ-12 (100) толщиной 380 мкм по методике, описанной в работах $[8,10]$. Захороненные слои в двухслойных структурах и модельные слои мезопористого кремния получали анодным травлением в электролите состава НF: $\mathrm{C}_{2} \mathrm{H}_{5} \mathrm{OH}$ при плотностях тока $8-25 \mathrm{MA} / \mathrm{cm}^{2}$ и временах травления 0.7-25 мин для получения слоев толщиной $0.3-10$ мкм.

Окисление структур проводилось в одностадийном $\left(1000^{\circ} \mathrm{C}\right.$, влажный кислород, 3 ч), двухстадийном $\left(350^{\circ} \mathrm{C}\right.$, сухой кислород, 30 мин и $1000^{\circ} \mathrm{C}$, влажный кислород, 3 ч), трехстадийном $\left(350^{\circ} \mathrm{C}\right.$, сухой кислород 30 мин; $800^{\circ} \mathrm{C}$, сухой кислород, 2 ч; $1100^{\circ} \mathrm{C}$, влажный кислород, 1 ч) режимах.

Исследование морфологии многослойных структур проводилось с помощью растрового электронного микроскопа (РЭМ) JEOL JSM-6610-LV с энергодисперсионным анализатором INCA-350. Для исследования поперечного среза структуры проводилась пробоподготовка методами склейки и излома. Метод склейки подразумевает склеивание двух частей исследуемого образца лицевыми сторонами с последующими механической шлифовкой и ионным травлением. За счет разной скорости ионного распыления проявляется ярко выраженная граница раздела между пористым и кристаллическим кремнием.

Исследование распределения химических элементов методом энергодисперсионного анализа (ЭДА) проводилось при пониженных ускоряющих напряжениях, что позволило уменьшить глубину зондирования и исключить ошибки в интерпретации данных ЭДА при исследовании поперечного сечения [11].

Исследование структуры и фазового состава изолирующего слоя проводилось методом спектральной эллипсометрии на модельных слоях толщиной до 1 мкм с помощью эллипсометра АСЭБ-10М (разработка ИФП СО РАН). В качестве модельных образцов применялись 
слои окисленного мезопористого кремния, полученные на поверхности монокристаллических подложек в технологических условиях, идентичных условиям получения захороненных слоев в многослойных структурах. Из анализа спектров эллипсометрических углов, измеренных в диапазоне длин волн 350-1050 нм и при угле падения $70^{\circ}$, определялись толщина и спектр показателя преломления модельных слоев. Из полученных данных на основе модели эффективной среды Бруггемана $[12,13]$ рассчитывались объемные доли $\mathrm{Si}, \mathrm{SiO}_{2}$ и пустот в формируемых слоях исходного и окисленного мезопористого кремния.

Исследование спектров инфракрасного (ИК) поглощения исходных и окисленных слоев в двухслойных структурах проводилось с помощью ИК фурье-спектрометра VERTEX 70 в спектральном интервале $400-7500 \mathrm{~cm}^{-1} \mathrm{c}$ разрешением $1 \mathrm{~cm}^{-1}$.

Электрофизические характеристики измерялись на LCR-метре Agilent E4980A. Исследование электрической прочности захороненного диэлектрика в двухслойных структурах и модельных окисленных мезопористых слоях проводилось при линейно нарастающем напряжении от $1 \mathrm{мB}$ до $300 \mathrm{~B}$ и скоростью $0.1-4 \mathrm{~B} / \mathrm{c}$. Из полученных вольт-амперных характеристик определялось напряжение пробоя $\left(U_{\mathrm{br}}\right)$ на структурах и оценивалась напряженность электрического поля пробоя $\left(E_{\mathrm{br}}\right)$. В качестве электродов к исследуемым образцам использовались In-Ga паста со стороны монокристаллического слоя и игольчатый электрод с радиусом кривизны острия порядка 100 мкм со стороны пористого кремния.

\section{3. Результаты и их обсуждение}

Как показали исследования, выполненные с помощью РЭМ, исследуемая двухслойная структура состоит из внешнего слоя макропористого кремния толщиной 7 мкм с вертикально ориентированными порами диаметром 1.3-1.6 мкм и захороненного слоя мезопористого кремния толщиной $\sim 6$ мкм (рис. 1 ). В процессе высокотемпературного окисления в атмосфере влажного кислорода при температуре $1000^{\circ} \mathrm{C}$ в течение трех часов происходит окисление захороненного мезопористого кремния по всей толщине, в то время как стенки макропор покрываются слоем окисла толщиной порядка 0.2 мкм. Поскольку окисление скелетона захороненного мезопористого слоя происходит путем проникновения кислорода через дно макропор, происходящий процесс можно представить как независимое друг от друга окисление областей мезопористого слоя под каждой макропорой. При этом происходит распространение фронта окисления как в глубину мезопористого слоя, так и в бок до полного смыкания с окисленной областью, формирующейся под соседней макропорой. В результате оставшиеся не окисленными участки кристаллических стенок макропор формируют заостренные области монокристаллического кремния („шипы“), проникающие в

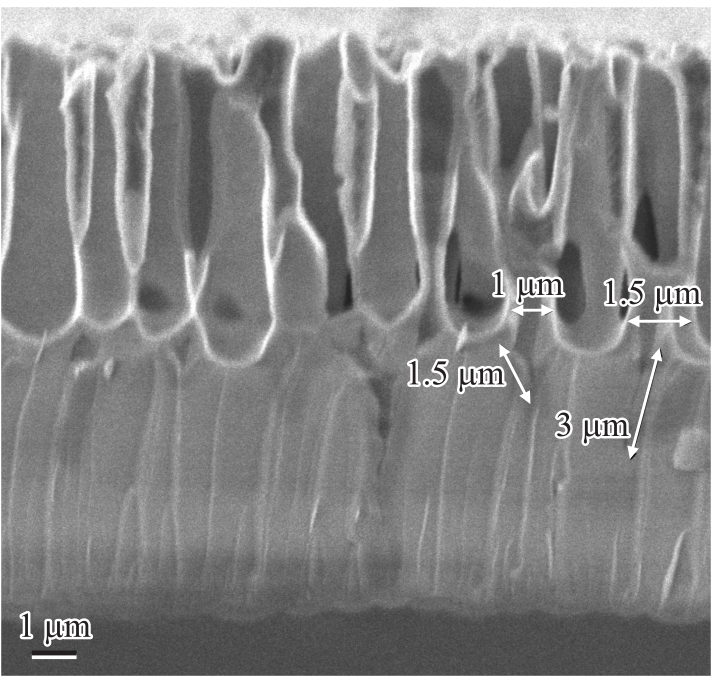

Рис. 1. РЭМ изображение двухслойной структуры „макропористый кремний-мезопористый кремний“ после одностадийного окисления.

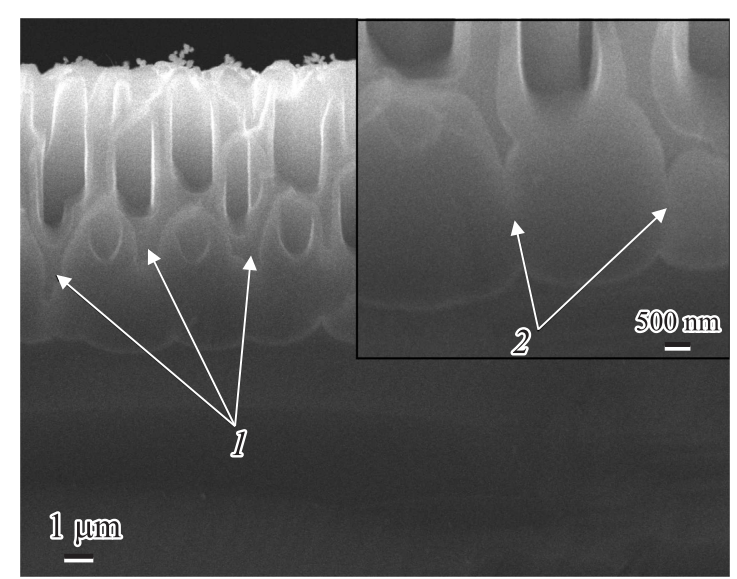

Рис. 2. РЭМ изображение начального этапа окисления двухслойной структуры „макропористый кремний-мезопористый кремний“. На вставке - РЭМ изображение окисленного слоя мезопористого кремния. 1 - „шипы“ неокисленного монокристаллического кремния; 2 - граница смыкания областей окисленного мезопористого кремния.

захороненный слой окисленного мезопористого кремния $[8,10]$. При окислении захороненных слоев мезопористого кремния монокристаллические „шипы“ оказываются изолированными как окислом на стенках макропор, так и окисленным захороненным слоем мезопористого кремния. Длина „шипов“ зависит от толщин стенок макропор, под которыми они формируются (рис. 1,2), и варьируется от 1 до 3 мкм для относительно тонких и толстых стенок соответственно. На изображениях, полученных с помощью РЭМ, на границе смыкания соседних окисленных областей в мезопористом кремнии наблюдается слабый контраст, который может быть обусловлен геттерированием примесей и дефектов гра- 
Таблица 1. Параметры модельного слоя мезопористого кремния до и после окисления. Эллипсометрические измерения

\begin{tabular}{|c|c|c|c|c|c|c|}
\hline $\begin{array}{c}\text { Состав } \\
\text { электролита } \\
\mathrm{HF}: \mathrm{C}_{2} \mathrm{H}_{5} \mathrm{OH}\end{array}$ & $\begin{array}{c}\text { Пористость } \\
\text { исходного } \\
\text { слоя, \% }\end{array}$ & $\begin{array}{c}\text { Толщина } \\
\text { исходного } \\
\text { слоя } h, \text { нм }\end{array}$ & $n_{0}$ & $\begin{array}{c}\text { Пористость } \\
\text { окисленного } \\
\text { слоя, \% }\end{array}$ & $\begin{array}{c}\text { Толщина } \\
\text { окисленного } \\
\text { слоя } D, \text { нм }\end{array}$ & $n_{\mathrm{ox}}$ \\
\hline \multicolumn{7}{|c|}{ Одностадийный режим окисления } \\
\hline $\begin{array}{l}(1: 2) \\
(1: 1) \\
(3: 1) \\
(3: 1) \\
(3: 1)\end{array}$ & $\begin{array}{l}74 \\
68 \\
64 \\
73 \\
65\end{array}$ & $\begin{array}{r}291 \\
373 \\
398 \\
647 \\
1050\end{array}$ & $\begin{array}{l}1.538 \\
1.736 \\
1.866 \\
1.556 \\
1.798\end{array}$ & $\begin{array}{r}28 \\
17 \\
0 \\
1 \\
0\end{array}$ & $\begin{array}{c}419 \\
451 \\
483 \\
625 \\
1080\end{array}$ & $\begin{array}{l}1.329 \\
1.428 \\
1.46 \\
1.455 \\
1.46\end{array}$ \\
\hline
\end{tabular}

Двухстадийный режим окисления

\begin{tabular}{c|c|c|c|c|c|c|c}
\hline$(3: 1)$ & 74 & 663 & 1.518 & 4 & 578 & 1.441 \\
\hline \multicolumn{7}{|c|}{ Трехстадийный режим окисления } \\
\hline$(3: 1)$ & 71 & 651 & 1.613 & 0 & 459 & 1.46
\end{tabular}

Примечание. $n_{0}$ и $n_{\mathrm{ox}}$ - показатель преломления в исходном и окисленном слоях при длине волны 550 нм соответственно.

ницей при росте окисла (рис. 2) [14,15]. Таким образом, изучение структуры с помощью РЭМ показало, что подбор оптимального режима анодного травления, обеспечивающий большую плотность макропор и меньшую толщину их стенок, позволяет существенно уменьшить глубину залегания „шипов“.

Картографирование распределения кислорода в структуре методом ЭДА (рис. 3) говорит о полном окислении захороненного мезопористого слоя и формировании стехиометрического окисла $\mathrm{SiO}_{2}$ при всех режимах окисления.

Для получения надежной электрической изоляции макропористого слоя от подложки необходимо создание сплошного плотного захороненного слоя окисла кремния, в то время как при окислении мезопористого кремния вероятно образование пористого окисла кремния. Известно, что даже низкотемпературное (до $400^{\circ} \mathrm{C}$ )

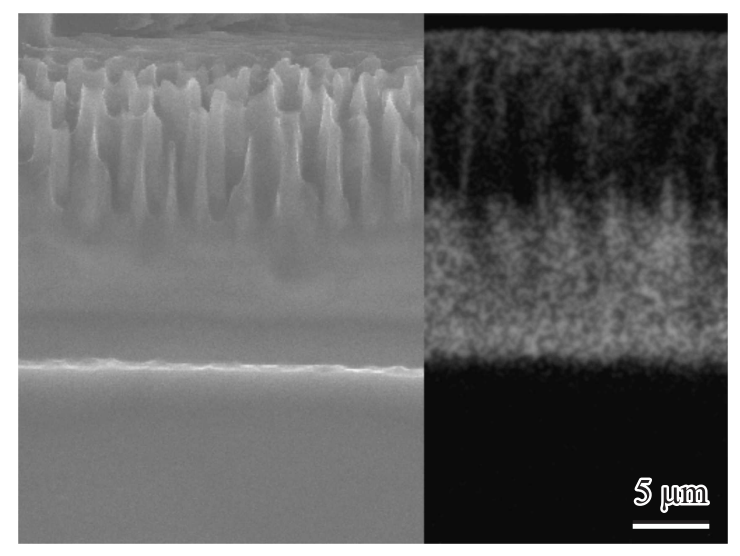

Рис. 3. РЭМ изображение двухслойной структуры „макропористый кремний-мезопористый кремний“ после окисления (слева) и карта распределения кислорода структуры (справа) по данным ЭДА. окисление мезопористого кремния приводит к полному окислению его поверхности [16]. Комбинирование температуры термообработок при окислении позволяет получать слои диэлектрика высокого качества. При первичном низкотемпературном окислении $\left(T=350^{\circ} \mathrm{C}\right)$ формируется сплошной тонкий слой окисла на стенках мезопористого кремния, что позволяет избежать разрушения мезопористого слоя при высокотемпературных обработках. Дальнейшее высокотемпературное окисление $\left(T=800^{\circ} \mathrm{C}\right)$ позволяет добиться достаточно полного окисления стенок пор. Финальная стадия $\left(T=1000^{\circ} \mathrm{C}\right.$, влажный кислород), как было показано в работе [16], приводит к дальнейшему уплотнению слоя окисла кремния.

Исследование параметров слоя захороненного $\mathrm{SiO}_{2}$ (толщины и сплошности) производилось методом спектральной эллипсометрии на модельных слоях (см. табл. 1). Представленные данные показывают, что для получения сплошного слоя окисла кремния пористость исходного мезопористого слоя должна быть близка к 60-65\%. При большей пористости мезопористого слоя формируется пористый слой двуокиси кремния, при меньшей - резко падает скорость окисления, обусловленная снижением скорости диффузии кислорода в глубь скелетона. Как показали эллипсометрические данные, при окислении структур в двух- и трехстадийном режимах наблюдается уменьшение толщины формирующегося слоя окисла - уплотнение слоя, которое практически не наблюдается при одностадийном режиме окисления (см. табл. 1).

Для контроля процесса термического окисления захороненного слоя мезопористого кремния применялась ИК-спектроскопия. Анализ основных полос ИК-поглощения на $\mathrm{Si}-\mathrm{O}-\mathrm{Si}$ связях в двухслойных структурах приведен в табл. 2. После высокотемпературного окисления в ИК-спектрах наблюдаются интенсивные полосы поглощения в диапазоне $1050-1230 \mathrm{~cm}^{-1}$, связанные с 
Таблица 2. Полосы ИК-поглощения на $\mathrm{Si}-\mathrm{O}-\mathrm{Si}$ связях, наблюдаемые в спектрах исходной и окисленной двухслойной структуры

\begin{tabular}{|c|c|c|}
\hline $\begin{array}{l}\text { Положение линий } \\
\text { поглощения, } \mathrm{cm}^{-1}\end{array}$ & Интерпретация & Ссылки \\
\hline \multicolumn{3}{|c|}{ Исходная двухслойная структура } \\
\hline 460 & $\delta(\mathrm{Si}-\mathrm{O}-\mathrm{Si})$ & {$[17]$} \\
\hline 807 & $v_{\mathrm{s}}(\mathrm{Si}-\mathrm{O}-\mathrm{Si})$, слабая & {$[17-19]$} \\
\hline 980 & $\begin{array}{c}v_{\text {as }} \text { кислорода в } \mathrm{Si}-\mathrm{O}-\mathrm{Si} \text { cis } \\
\text { и trans конфигурациях }\end{array}$ & {$[20,21]$} \\
\hline 1100 & $\begin{array}{c}v_{\mathrm{as}}(\mathrm{Si}-\mathrm{O}-\mathrm{Si}) \\
\text { в стехиометрическом } \mathrm{SiO}_{2}\end{array}$ & {$[17,19,21$} \\
\hline 1200 & $\begin{array}{c}\mathrm{LO} v(\mathrm{Si}-\mathrm{O}-\mathrm{Si}) \\
\text { в тонком слое } \mathrm{SiO}_{2}\end{array}$ & {$[22,23]$} \\
\hline
\end{tabular}

\begin{tabular}{c|c|c}
\hline \multicolumn{3}{c}{$\begin{array}{c}\text { Окисленная двухслойная структура } \\
\text { (трехстадийное окисление) }\end{array}$} \\
\hline 465 & $\delta(\mathrm{Si}-\mathrm{O}-\mathrm{Si})$, рост полосы & {$[17]$} \\
\hline $800-808$ & $v_{\mathrm{s}}(\mathrm{Si}-\mathrm{O}-\mathrm{Si})$, рост полосы & {$[17-19]$} \\
\hline 1050 & Нестехиометрический $\mathrm{Si}_{2} \mathrm{O}_{3}$ & {$[21]$} \\
\hline $1070-1080$ & $\begin{array}{c}\text { Стехиометрический } \mathrm{SiO}_{2}, \\
\text { преобладающий пик }\end{array}$ & {$[17,19,21]$} \\
\hline 1230 & Нанокластерный $\mathrm{SiO}_{2}$ & {$[20,21]$}
\end{tabular}

Примечание. $\delta$ - деформационное колебание, $v-$ валентное, as антисимметричное, $\mathrm{s}$ - симметричное. присутствием окисла кремния в различных фазах: от нестехиометрического $\left(1050 \mathrm{~cm}^{-1}\right)$ [21] до нанокластерного $\mathrm{SiO}_{2}\left(1230 \mathrm{~cm}^{-1}\right)$ [20,21] с преобладанием стехиометрического окисла $\left(1070-1080 \mathrm{~cm}^{-1}\right)$ [17,19,21].

Проведенные исследования позволили определить оптимальные условия для получения захороненного изолирующего слоя. Для уменьшения длины монокристаллических „шипов“ необходимо создание внешнего слоя макропористого кремния с минимальной толщиной стенок между порами. Формирование в составе структуры мезопористого кремния с пористостью около $60 \%$, толщиной более 5 мкм позволяет получать полностью окисленные плотные захороненные слои окисла кремния, в которых кристаллические „шипы“ остаются изолированными слоем диэлектрика. Высокотемпературное окисление приводит к формированию слоя стехиометрического окисла кремния, а применение трехстадийного окисления позволяет получать наиболее плотный захороненный слой диэлектрика.

Сравнение электрофизических характеристик захороненного окисленного мезопористого слоя в двухслойных структурах и модельных окисленных слоев мезопористого кремния (см. табл. 3, 4) показало, что для модельных окисленных слоев мезопористого кремния, полученных в тех же режимах, что и захороненные мезопористые слои в двухслойных структурах, величина напряженности электрического поля пробоя $E_{\mathrm{br}}$ составляет $\sim 10^{6} \mathrm{~B} / \mathrm{cm}$, что близко к значениям $E_{\mathrm{br}}$ для окисла, полученного на монокристаллическом кремнии [24]. Для образцов окисленных двухслойных структур напря-

Таблица 3. Электрофизические характеристики модельных окисленных слоев мезопористого кремния

\begin{tabular}{c|c|c|c|c}
\hline $\begin{array}{c}\text { Толщина окисленного } \\
\text { мезопористого } \\
\text { слоя, мкм }\end{array}$ & $\begin{array}{c}\text { Режим } \\
\text { окисления }\end{array}$ & $\begin{array}{c}\text { Напряжение } \\
\text { пробоя слоя } U_{\mathrm{br}}, \mathrm{B}\end{array}$ & $\begin{array}{c}\text { Напряженность } \\
\text { электрического } \\
\text { поля } E_{\mathrm{br}}, \mathrm{B} / \mathrm{cm}\end{array}$ & $\begin{array}{c}\text { Ток утечки } \\
\text { при } 10 \mathrm{~B} I_{\mathrm{L}}, \mathrm{HA}\end{array}$ \\
\hline 0.625 & Одностадийный & 170 & $2.7 \cdot 10^{6}$ & 1 \\
0.578 & Двухстадийный & 150 & $2.6 \cdot 10^{6}$ & 1 \\
0.459 & Трехстадийный & 300 & $6.5 \cdot 10^{6}$ & 1 \\
3.1 & Двухстадийный & 300 & $1 \cdot 10^{6}$ & 10 \\
& Трехстадийный & 300 & $0.9 \cdot 10^{6}$ & 10
\end{tabular}

Таблица 4. Электрофизические характеристики окисленных двухслойных структур*

\begin{tabular}{c|c|c|c|c|c}
\hline $\begin{array}{c}\text { Толщина окисленного } \\
\text { мезопористого } \\
\text { слоя, мкм }\end{array}$ & $\begin{array}{c}\text { Длина } \\
\text { „шипов“, мкм }\end{array}$ & $\begin{array}{c}\text { Режим } \\
\text { окисления }\end{array}$ & $\begin{array}{c}\text { Напряжение } \\
\text { пробоя слоя } U_{\mathrm{br}}, \mathrm{B}\end{array}$ & $\begin{array}{c}\text { Напряженность } \\
\text { электрического } \\
\text { поля } E_{\mathrm{br}}, \mathrm{B} / \mathrm{cm}\end{array}$ & $\begin{array}{c}\text { Ток утечки } \\
\text { при } 10 \mathrm{~B} I_{\mathrm{L}}, \mathrm{HA}\end{array}$ \\
\hline 8.6 & 2 & Одностадийный & 10 & $1.2 \cdot 10^{4}$ & 2 \\
6.7 & 1.8 & $\ll$ & 25 & $3.7 \cdot 10^{4}$ & 1 \\
6.5 & 1.2 & $\ll$ & 140 & $2.2 \cdot 10^{5}$ & 1 \\
4.3 & 1.8 & Двухстадийный & 5 & $1.2 \cdot 10^{4}$ & 10 \\
2.7 & 1.2 & $\ll$ & 14 & $0.5 \cdot 10^{5}$ & 10 \\
4.1 & 1.2 & Трехстадийный & 210 & $5.1 \cdot 10^{5}$ & 1
\end{tabular}

Примечание. * Толщина окисленного мезопористого слоя и длина „шипов“, измеренные по данным РЭМ. 
женность электрического поля для пробоя составляет $E_{\mathrm{br}} \sim 10^{4}-10^{5} \mathrm{~B} / \mathrm{cm}$, что обусловлено значительными напряженностями электрического поля на концах кремниевых „шипов“ в стенках пор.

\section{4. Заключение}

В результате проведенных исследований изучен процесс формирования захороненного изолирующего слоя двуокиси кремния и получены оптимальные режимы окисления слоя мезопористого кремния в двухслойных структурах „макропористый кремний-мезопористый кремний“. Установлено, что для получения сплошного слоя окисла кремния на подложке кремния $p$-типа пористость исходного слоя должна быть близка к $60 \%$. При окислении в трехстадийном режиме (последовательно в атмосфере сухого и влажного кислорода) в двухслойной структуре наблюдались стабильные пробивные характеристики с $E_{\mathrm{br}} \sim 5 \cdot 10^{5} \mathrm{~B} / \mathrm{cm}$.

Многослойная структура „пористый кремний-наизоляторе“, обладая развитой поверхностью и надежной изоляцией, является перспективной для применения в интегрированных химических микро- и наносенсорах.

Работа выполнена при частичной поддержке грантов РФФИ № 15-48-04134-р_сибирь_а и № 16-08-00763-а.

\section{Список литературы}

[1] W.I. Laminack, J.L. Gole. Nanomaterials, 3, 469 (2013).

[2] V.A. Moshnikov, I. Gracheva, A.S. Lenshin, Y.M. Spivak, M.G. Anchkov, V.V. Kuznetsov, J.M. Olchowik. J. Non-Cryst. Sol., 358, 590 (2012).

[3] L. Zhao, M. Yosef, M. Steinhart, P. Goring, H. Hofmeister, U. Gosele, S. Schlecht. Angew. Chem. Int. Ed., 45, 311 (2006).

[4] R. Triantafyllopoulou, X. Illa, O. Casals, S. Chatzandroulis, C. Tsamis, A. Romano-Rodriguez, J.R. Morante. Microelectron. Eng., 85, 1116 (2008).

[5] V.M. Arakelyan, Kh.S. Martirosyan, V.E. Galstyan, G.E. Shahnazaryan, V.M. Aroutiounian. Phys. Status. Solidi C, 4 (6), 2059 (2007).

[6] F.A. Garces, L.N. Acquaroli, R. Urteaga, A. Dussan, R.R. Koropecki, R.D. Arce. Thin Sol. Films, 520 (13), 4254 (2012).

[7] N. Sankara Subramanian, R. Vivek Sabaapathy, P. Vickraman, G. Vimal Kumar, R. Sriram, B. Santhi. Ionics, 13, 323 (2007).

[8] В.В. Болотов, В.Е. Росликов, Е.А. Росликова, К.Е. Ивлев, Е.В. Князев, Н.А. Давлеткильдеев. ФТП, 48, 412 (2014).

[9] В.В. Болотов, В.Е. Росликов, К.Е. Ивлев, Е.В. Князев. Патент РФ № 2554298 C1 (2015).

[10] V.V. Bolotov, K.E. Ivlev, E.V. Knyazev, V.E. Roslikov, I.V. Ponomareva. Procedia Engin., 113, 506 (2015).

[11] M.D. Frey. Scanning Microscopy for Nanotechnology Techniques and Applications, ed. by W. Zhou, Z.L. Wang (Springer Science+Business Media, LLC, 2006) p. 101.

[12] H. Fujiwara. Spectroscopic ellipsometry: principles and applications (Chichester, John Wiley \& Sons Ltd, 2007) p. 177.

[13] В.В. Болотов, Н.А. Давлеткильдеев, А.А. Коротенко, В.Е. Росликов, Ю.А. Стенькин. ЖТФ, 81 (11), 52 (2011).
[14] V.V. Bolotov, M.D. Efremov, I. Babanskaya, K. Schmalz. Mater. Sci. Eng., B, 21, 49 (1993).

[15] V.V. Bolotov, M.D. Efremov, V.M. Emeksuzyan, K. Schmalz. Sol. St. Phenomena, 19-20, 13 (1991).

[16] J.J. Yon, K. Barla, R. Herino, G. Bomchil. J. Appl. Phys., 62, 1042 (1987).

[17] W. Theiß. Surf. Sci. Reports, 29, 91 (1997).

[18] А.В. Васин, П.Н. Охолин, И.Н. Веровский, А.Н. Назаров, В.С. Лысенко, К.И. Холостов, В.П. Бондаренко, Y. Ishikawa. ФТП, 45, 360 (2011).

[19] А.А. Копылов, А.Н. Холодилов. ФТП, 31, 556 (1997).

[20] Ю.К. Ундалов, Е.И. Теруков. ФТП, 49, 887 (2015).

[21] Ch. Hollenstein, A. A. Howling, C. Courteille, D. Magni, S.M. Scholz, G.M.W. Kroesen, N. Simons, W. de Zeeuw, W. Schwarzenbach. J. Phys. D: Appl. Phys., 31, 74 (1998).

[22] А.И. Белогорохов, Л.И. Белогорохова. ФТП, 33, 198 (1999).

[23] А.С. Леньшин, В.М. Кашкаров, П.В. Середин, Ю.М. Спивак, В.А. Мошников. ФТП, 45, 1229 (2011).

[24] П.Дж. Херроп, Д.С. Кемпелл. Технология тонких пленок. Справочник, под ред. Л. Майссела, Р. Глэнга (М., Сов. радио, 1977) т. 2, с. 469.

Редактор А.Н. Смирнов

\section{Formation and properties of the buried isolating silicon oxide layer in the double-layered structures ,porous silicon-on-insulator"}

V.V. Bolotov, E.V. Knyazev, I.V. Ponomareva, V.E. Kan,
N.A. Davletkildeev, K.E. Ivlev, V.E. Roslikov

Omsk Scientific Center of Siberian Branch

of Russian Academy of Sciences,

644024 Omsk, Russia

\begin{abstract}
The oxidation process of mesoporous silicon in the double-layered structures „macroporous silicon-mesoporous silicon" has been studied. The morphology and dielectric properties of the buried silicon dioxide layer have been investigated by means of electron microscopy, ellipsometry, and electro physical measurements. The presence of the specific defects, so called „spikes", has been revealed. These „spikes“ occur between the oxidized macropore walls in the macroporous silicon layer and the crossing fronts of oxidation in the buried mesoporous silicon layer. It was found that the initial porosity of the buried mesoporous silicon layer near $60 \%$ and a three-stage thermal oxidation lead to formation of the buried silicon oxide layers with the intensity of the electric field for breakdown $E_{\mathrm{br}} \sim 10^{4}-10^{5} \mathrm{~V} / \mathrm{cm}$. The multilayered structures ,porous silicon-on-insulator“ are prospective for integrated chemical micro- and nanosensors.
\end{abstract}

